\title{
Vitamin D and thyroid disorders: a systematic review and Meta-analysis of observational studies
}

\author{
Sorour Taheriniya ${ }^{1}$, Arman Arab², Amir Hadi ${ }^{3}$, Abdulmannan Fadel ${ }^{4}$ and Gholamreza Askari ${ }^{2 *}$ (D)
}

\begin{abstract}
Background: The contribution of vitamin D to thyroid disorders has received paramount attention; however, results are mixed. Hence, we designed a systematic review and meta-analysis to obtain a definitive conclusion.

Methods: The search included PubMed, ISI Web of Science, Scopus, and Google Scholar databases up to March 2021 to collect available papers reporting the relationship between serum levels of vitamin D and thyroid disorders. The pooled effect was reported as weighted mean difference (WMD) and 95\% confidence interval (Cl).

Results: Out of 6123 datasets, 42 were eligible to get into this systematic review and meta-analysis. Serum vitamin D was markedly lower in autoimmune thyroid diseases (AITD) (WMD $-3.1 \mathrm{ng} / \mathrm{dl} ; 95 \% \mathrm{Cl},-5.57$ to $-0.66 ; P=0.013$; $\left.\mathrm{I}^{2}=99.9 \%\right)$, Hashimoto's thyroiditis (HT) (WMD $-6.05 \mathrm{ng} / \mathrm{dl} ; 95 \% \mathrm{Cl},-8.35$ to $\left.-3.75 ; P<0.001 ; \mathrm{I}^{2}=91.0 \%\right)$ and hypothyroidism patients (WMD $-13.43 \mathrm{ng} / \mathrm{dl} ; 95 \% \mathrm{Cl},-26.04$ to $-0.81 ; P=0.03 ; \mathrm{I}^{2}=99.5 \%$ ), but not in subjects with Graves' disease (GD) (WMD $-4.14 \mathrm{ng} / \mathrm{dl} ; 95 \% \mathrm{Cl},-8.46$ to $0.17 ; P=0.06 ; I^{2}=97.5 \%$ ).

Conclusions: Our findings suggested lower vitamin D levels in patients with hypothyroidism, AITD, and HT compared to healthy subjects. However, the link between serum vitamin D and GD was only significant among subjects $\geq 40$ years old.
\end{abstract}

Keywords: Vitamin D, Thyroid disorders, Systematic review, meta-analysis

\section{Background}

Vitamin $D$ is an essential fat-soluble nutrient with hormone-like activity [1, 2]. Vitamin D deficiency is among the most common health problems in the world in all age groups, even in low latitude countries with sufficient UV radiation or industrialized countries with a long history of vitamin D fortification strategies. Previous studies have indicated that about one billion people around the world have been diagnosed with vitamin D deficiency [3]. Recent evidence has shown the prevalence of vitamin D deficiency in both developed and

\footnotetext{
* Correspondence: askari@mui.ac.ir

${ }^{2}$ Department of Community Nutrition, School of Nutrition and Food Science, Food Security Research Center, Isfahan University of Medical Sciences, Isfahan, Iran

Full list of author information is available at the end of the article
}

developing countries, which in Europe is 13\% and in the United States 19\% [4-6]. Vitamin D deficiency has increased in recent years in Iran, and reports have revealed that the vitamin D deficiency rate is nearly $50 \%$ [2]. Risk factors for vitamin D deficiency include aging, female sex, winter season, obesity, malnutrition, lack of sun exposure, and dark skin pigmentation [7]. Accordingly, sufficient attention to vitamin $\mathrm{D}$ deficiency diagnosis is needed for treatment to decrease its undesirable effects on human health.

Over the last decades, numerous studies have indicated that low serum vitamin D levels are associated with a series of diseases such as high blood pressure, heart disease, diabetes, cancer, mood disorders, multiple sclerosis, and autoimmune diseases $[8,9]$. This vitamin

(c) The Author(s). 2021 Open Access This article is licensed under a Creative Commons Attribution 4.0 International License, which permits use, sharing, adaptation, distribution and reproduction in any medium or format, as long as you give appropriate credit to the original author(s) and the source, provide a link to the Creative Commons licence, and indicate if changes were made. The images or other third party material in this article are included in the article's Creative Commons licence, unless indicated otherwise in a credit line to the material. If material is not included in the article's Creative Commons licence and your intended use is not permitted by statutory regulation or exceeds the permitted use, you will need to obtain permission directly from the copyright holder. To view a copy of this licence, visit http://creativecommons.org/licenses/by/4.0/ The Creative Commons Public Domain Dedication waiver (http://creativecommons.org/publicdomain/zero/1.0/) applies to the data made available in this article, unless otherwise stated in a credit line to the data. 
exerts its biological actions through nuclear vitamin $\mathrm{D}$ receptors (VDR) that reside in most human cells and tissues [10]. Hence, vitamin D plays its role through the regulation of gene expression in places where its receptors exist, such as the endocrine system [11].

The thyroid gland is one of the largest endocrine glands with many roles for homeostatic control, including growth, energy expenditure, and metabolism [12, 13]. Any thyroid disorder could result in a cluster of metabolic ailments [12-14]. Recent literature has illustrated the presumed association between serum vitamin $\mathrm{D}$ and thyroid diseases [15]. This association results from the presence of similar receptors for vitamin D and thyroid hormones, named steroid or nuclear hormone receptors. These shreds of evidence show the importance of the role of vitamin $\mathrm{D}$ in thyroid function and the association between vitamin $\mathrm{D}$ deficiency and thyroid diseases. However, some studies observed no significant relationship [16-18]. Therefore, we conducted a systematic review and meta-analysis to survey all observational studies regarding the association between serum vitamin D levels and thyroid disorders, including hypothyroidism, autoimmune thyroid disease (AITD), Hashimoto's thyroiditis (HT), and Graves' disease (GD) among the adult population.

\section{Methods}

After registration on the Prospero database (CRD42020187237), this dataset was conceived pursuant to the Preferred Reporting Items for Systematic Reviews and Meta-analysis (PRISMA) statement [19].

\section{Search strategy}

We performed a systematic literature search up to March 2021 in four databases, including PubMed, ISI Web of Science, Scopus, and Google Scholar to find papers reporting the relationship between serum levels of vitamin $\mathrm{D}$ and thyroid disorders. The terms used for the database search were "vitamin D" OR "25-hydroxyvitamin D" OR "1,25-dihydroxyvitamin D" OR "cholecalciferol" OR "ergocalciferol" OR "calcitriol" OR "vitamin $\mathrm{D}_{3}$ " AND "hypothyroidism" OR "hypothyroid" OR "thyroid disorder" OR "triiodothyronine" OR "thyroxin" OR "thyroid stimulating hormone" OR "thyroid hormones" OR "hyperthyroidism" OR "hyperthyroid" OR "autoimmune thyroiditis" OR "anti-thyroid peroxidase" OR "Graves" disease", OR "Hashimoto's thyroiditis". The authors also screened the reference sections of the contained articles to spot any other eligible studies not captured via the online database search.

\section{Study selection}

Before the screening process, all search results were exported into the EndNote X7 software (Thomson
Corporation, Stamford, USA). Original observational human studies (case-control or cross-sectional) about the association between serum vitamin $\mathrm{D}$ and thyroid disorders with reported means, medians, or odds ratios (ORs), and the corresponding 95\% confidence intervals (CIs) were included. Studies that recruited women during pregnancy or lactation, non-human datasets, reviews, case reports, editorials, poster abstracts, non-original, or irrelevant datasets were excluded. Two investigators were responsible for the selection process to lower the potential error (S. T \& A. A). The difference of opinion was dealt with the cooperation of a third reviewer (G. A).

\section{Data extraction}

The data of interest were extracted from each study using a predefined excel form in a duplicate and blinded manner. For each study, the extracted information was as follows: first author's name, publication year, location, sample size, sex, age, body mass index (BMI), study design, vitamin D assay method, the season of sample collection, and population health status. Two independent reviewers conducted the processes of data extraction (S. T \& A. A). The difference of opinion on a given study was dealt with via discussion, and if necessary, arbitration by a third reviewer (G. A).

\section{Study quality assessment}

According to the Newcastle-Ottawa Quality Assessment Scale for observational studies [20], authors assessed the quality of the included studies on three domains: selection (5 points), comparability ( 2 points), and outcome (3 points). Scores of $7-10,5-6$, and $0-4$ indicate high, moderate, and low-quality studies, respectively [21].

\section{Statistical analysis}

Authors run a meta-analysis, including weighted mean difference (WMD) with 95\% CIs plus a random effect model, to estimate the quantitative summary of the association between vitamin $\mathrm{D}$ and thyroid disorders, including hypothyroidism, AITD, HT, and GD. Mean \pm standard deviation (SD) was extracted to estimate the pooled effects using WMD. For datasets with a standard error (SE), SD was determined using the following equation: $\mathrm{SE} \times \sqrt{ }$. Related equations were used to obtain the preferred data out of the median \pm range or interquartile range [22]. If a study presented analyses stratified by certain key variables such as participants' health status, stratified estimates were assumed to be independent of each other and included as a separate unit of observation in the meta-analysis. To assess the influence of each study on the stability of the meta-analysis results, the authors carried out a sensitivity analysis. Moreover, subgroup analysis based on age, gender, geographical population, study design, and population health status 
was executed whenever it was possible. STATA software, version 11.2 (Stata Corp, College Station, TX, USA) was used for data analysis with $P$-values $<0.05$ considered as statistically significant. Heterogeneity was checked using the $\mathrm{I}^{2}$ index. $\mathrm{I}^{2}$ index equal to 25,50 , or $75 \%$ represents low, moderate, and high heterogeneity, respectively [23]. The funnel plots were visually inspected to detect any publication bias, and Egger's and Begg's tests defined the extent of funnel plot asymmetry [24].

\section{Results}

\section{Search results}

Our initial search through databases identified a total of 6123 papers. With duplicates removed, the 3062 remaining articles were examined based on the review of the titles and abstracts by two independent reviewers. Authors retrieved and reviewed 98 articles based on the full text, and finally, 35 studies were eligible to get into the current study. Moreover, the works of Bouillon et al. [25], Unal et al. [26], Ma et al. [27], Ke et al. [28], Fawzy et al. [29], Toulis et al. [30], and Komisarenko et al. [31] were divided into two different studies. Therefore, a total of 42 eligible studies were included in the meta-analysis. The PRISMA flowchart briefly states the results of the study selection process (Fig. 1).

\section{Overview of included studies}

A total of 35 studies (42 arms), including 28 casecontrol $[17,25-51]$ and 7 cross-sectional studies [5258] with sample sizes varying from 38 to 6685 subjects were included in our systematic review. The selected studies were published between 1980 and 2018. Among these, 9 studies were from Turkey [26, 34, 36, 37, 39, 42,

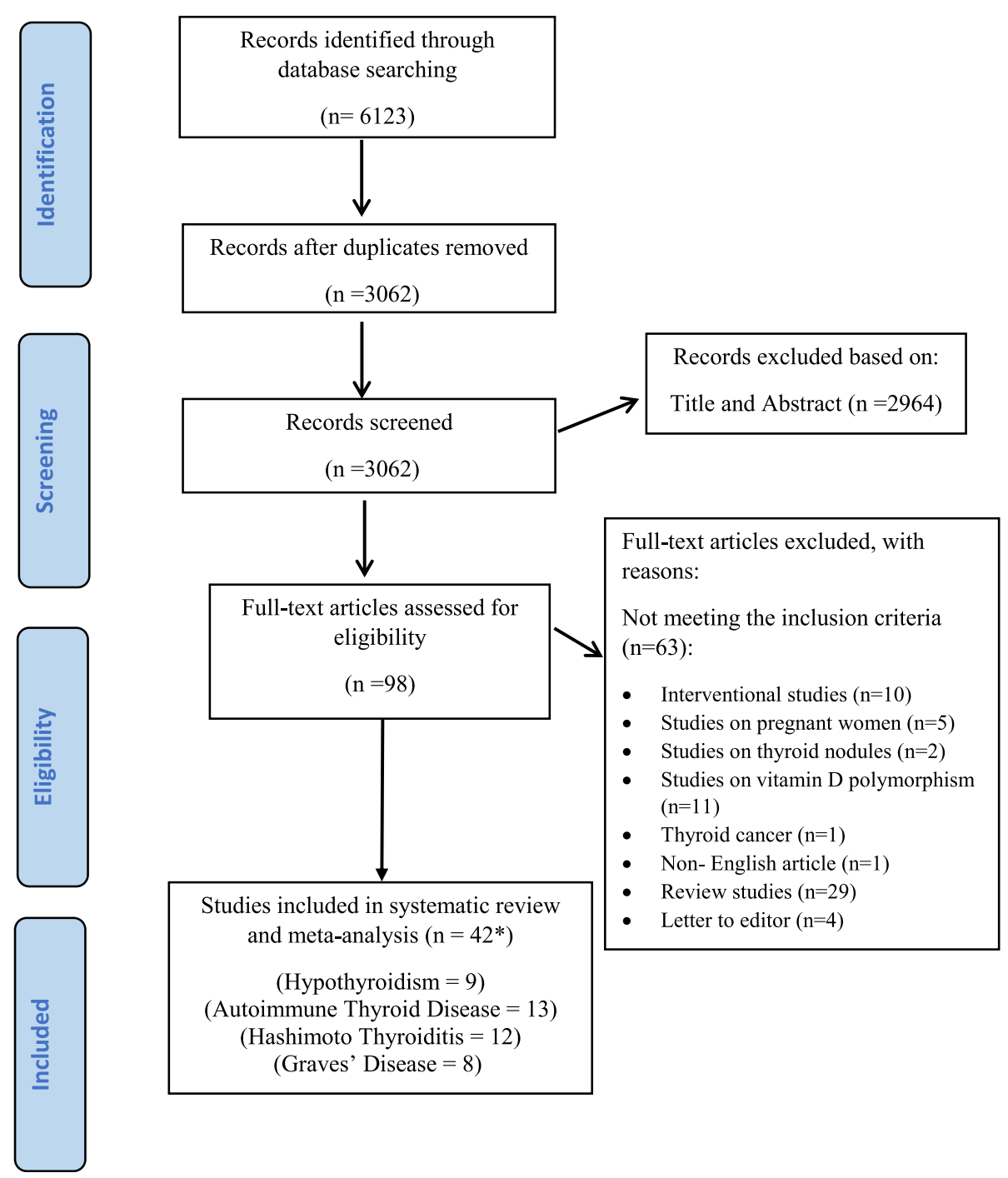

Fig. 1 The flow diagram of study selection 
Table 1 Characteristics of included studies

\begin{tabular}{|c|c|c|c|c|c|c|c|c|c|}
\hline Author, Year & Location & $\begin{array}{l}\text { Sample } \\
\text { size (F/M) }\end{array}$ & $\begin{array}{l}\text { Age } \\
\text { (year) }\end{array}$ & $\begin{array}{l}\mathrm{BMI} \\
(\mathrm{kg} / \\
\left.\mathrm{m}^{2}\right)\end{array}$ & $\begin{array}{l}\text { Study } \\
\text { design }\end{array}$ & $\begin{array}{l}\text { Population } \\
\text { health status }\end{array}$ & $\begin{array}{l}\text { Vit D assay } \\
\text { method }\end{array}$ & $\begin{array}{l}\text { Season of } \\
\text { sample } \\
\text { collection }\end{array}$ & $\begin{array}{l}\text { Quality } \\
\text { assessment } \\
\text { score }\end{array}$ \\
\hline $\begin{array}{l}\text { Bouillon et al., } \\
1980 \text { (a) }\end{array}$ & Belgium & $69 / 24$ & 42 & - & $\begin{array}{l}\text { Case- } \\
\text { control }\end{array}$ & $\begin{array}{l}\text { Hypothyroid } \\
\text { patients }\end{array}$ & RIA & - & Moderate \\
\hline $\begin{array}{l}\text { Bouillon et al., } \\
1980 \text { (b) }\end{array}$ & Belgium & $77 / 27$ & 39 & - & $\begin{array}{l}\text { Case- } \\
\text { control }\end{array}$ & $\mathrm{GD}$ & RIA & - & Moderate \\
\hline $\begin{array}{l}\text { Camurdan et al., } \\
2012\end{array}$ & Turkey & $126 / 26$ & 12.05 & - & $\begin{array}{l}\text { Case- } \\
\text { control }\end{array}$ & HT & HPLC & - & Low \\
\hline Yasuda et al., 2012 & Japan & $72 \mathrm{~F}$ & 40.8 & 21.75 & $\begin{array}{l}\text { Case- } \\
\text { control }\end{array}$ & $\mathrm{GD}$ & $\begin{array}{l}\text { Competitive protein } \\
\text { binding assay }\end{array}$ & Winter, spring & Moderate \\
\hline $\begin{array}{l}\text { Jyotsna et al., } \\
2012\end{array}$ & India & $124 / 36$ & 36.37 & 22.05 & $\begin{array}{l}\text { Case- } \\
\text { control }\end{array}$ & $\mathrm{GD}$ & RIA & All season & Moderate \\
\hline $\begin{array}{l}\text { Chailurkit et al., } \\
2012\end{array}$ & Thailand & $1292 / 1290$ & 55 & 23.3 & $\begin{array}{l}\text { Cross- }^{-} \\
\text {sectional }\end{array}$ & AITD & HPLC & All season & High \\
\hline $\begin{array}{l}\text { Bozkurt et. al., } \\
2013\end{array}$ & Turkey & $369 / 171$ & 42.5 & 28.4 & $\begin{array}{l}\text { Case- } \\
\text { control }\end{array}$ & HT & ELISA & Summer & Moderate \\
\hline $\begin{array}{l}\text { Mackawy et al., } \\
2013\end{array}$ & $\begin{array}{l}\text { Saudi } \\
\text { Arabia }\end{array}$ & $35 / 25$ & 46.38 & - & $\begin{array}{l}\text { Case- } \\
\text { control }\end{array}$ & $\begin{array}{l}\text { Hypothyroid } \\
\text { patients }\end{array}$ & Spectrophotometry & $\begin{array}{l}\text { Autumn, winter, } \\
\text { spring }\end{array}$ & Moderate \\
\hline $\begin{array}{l}\text { Aljohani et al., } \\
2013\end{array}$ & $\begin{array}{l}\text { Saudi } \\
\text { Arabia }\end{array}$ & $85 / 9$ & 35.8 & 30.05 & $\begin{array}{l}\text { Case- } \\
\text { control }\end{array}$ & $\begin{array}{l}\text { Hypothyroid } \\
\text { patients }\end{array}$ & ELISA & - & Moderate \\
\hline $\begin{array}{l}\text { Fawzy et al., } 2013 \\
\text { (a) }\end{array}$ & Egypt & $43 / 8$ & 32.39 & - & $\begin{array}{l}\text { Case- } \\
\text { control }\end{array}$ & $\begin{array}{l}\text { Subclinical } \\
\text { hypothyroid }\end{array}$ & CLIA & All season & Low \\
\hline $\begin{array}{l}\text { Fawzy et al., } 2013 \\
\text { (b) }\end{array}$ & Egypt & $44 / 12$ & 31.66 & - & $\begin{array}{l}\text { Case- } \\
\text { control }\end{array}$ & $\begin{array}{l}\text { Hypothyroid } \\
\text { patients }\end{array}$ & CLIA & All season & Low \\
\hline Ucar et al., 2014 & Turkey & $62 / 15$ & 74.95 & - & $\begin{array}{l}\text { Case- } \\
\text { control }\end{array}$ & $\begin{array}{l}\text { Subclinical } \\
\text { hypothyroid }\end{array}$ & CLIA & - & Moderate \\
\hline $\begin{array}{l}\text { Unal et al., } 2014 \\
\text { (a) }\end{array}$ & Turkey & 378 F\&M & 44.6 & - & $\begin{array}{l}\text { Case- } \\
\text { control }\end{array}$ & HT & CLIA & - & Low \\
\hline $\begin{array}{l}\text { Unal et al., } 2014 \\
\text { (b) }\end{array}$ & Turkey & $151 \mathrm{~F} \& \mathrm{M}$ & 44.6 & - & $\begin{array}{l}\text { Case- } \\
\text { control }\end{array}$ & $G D$ & CLIA & - & Low \\
\hline Demir et al., 2014 & Turkey & $24 / 14$ & 12.95 & - & $\begin{array}{l}\text { Case- } \\
\text { control }\end{array}$ & AITD & - & - & Moderate \\
\hline Zhang et al., 2014 & China & $84 / 56$ & 32.34 & 20.57 & $\begin{array}{l}\text { Case - } \\
\text { control }\end{array}$ & $\mathrm{GD}$ & ELISA & Summer, autumn & Moderate \\
\hline Shin et al., 2014 & Korea & $267 / 37$ & 49.9 & - & $\begin{array}{l}\text { Cross } \\
\text { sectional }\end{array}$ & AITD & RIA & All season & High \\
\hline Choi et al., 2014 & Korea & $2793 / 3892$ & 54.1 & 24.2 & $\begin{array}{l}\text { Cross- }^{-} \\
\text {sectional }\end{array}$ & AITD & RIA & All season & Moderate \\
\hline $\begin{array}{l}\text { Evliyaoglu et al., } \\
2015\end{array}$ & Turkey & $117 / 52$ & 12.08 & - & $\begin{array}{l}\text { Case- } \\
\text { control }\end{array}$ & HT & HPLC & $\begin{array}{l}\text { Winter, spring, } \\
\text { summer }\end{array}$ & Moderate \\
\hline Ma et al., 2015 (a) & China & $100 / 40$ & 41.05 & 28.18 & $\begin{array}{l}\text { Case- } \\
\text { control }\end{array}$ & HT & ECLA & $\begin{array}{l}\text { Autumn, winter, } \\
\text { spring }\end{array}$ & Moderate \\
\hline Ma et al., 2015 (b) & China & $97 / 43$ & 41.01 & 28.18 & $\begin{array}{l}\text { Case- } \\
\text { control }\end{array}$ & $G D$ & ECLA & $\begin{array}{l}\text { Autumn, winter, } \\
\text { spring }\end{array}$ & Moderate \\
\hline $\begin{array}{l}\text { Maciejewski et al., } \\
2015\end{array}$ & Poland & $84 / 10$ & 47.62 & - & $\begin{array}{l}\text { Case- } \\
\text { control }\end{array}$ & HT & ELISA & Spring & Moderate \\
\hline $\begin{array}{l}\text { Toulis et al., } 2015 \\
\text { (a) }\end{array}$ & Greece & $264 \mathrm{~F} \& \mathrm{M}$ & 67.6 & 31.6 & $\begin{array}{l}\text { Case - } \\
\text { control }\end{array}$ & AlTD+T2DM & RIA & Winter, spring & Moderate \\
\hline $\begin{array}{l}\text { Toulis et al., } 2015 \\
\text { (b) }\end{array}$ & Greece & $234 \mathrm{~F} \& \mathrm{M}$ & 72.2 & 30.6 & $\begin{array}{l}\text { Case - } \\
\text { control }\end{array}$ & $\begin{array}{l}\text { AlTD+control } \\
\text { group }\end{array}$ & RIA & Winter, spring & Moderate \\
\hline $\begin{array}{l}\text { Muscogiuri et al., } \\
2015\end{array}$ & Italy & $50 \mathrm{~F}$ & 26.8 & 28.1 & $\begin{array}{l}\text { Cross- } \\
\text { sectional }\end{array}$ & AITD+PCOS & CLIA & Spring, summer & High \\
\hline $\begin{array}{l}\text { Metwalley et al., } \\
2015\end{array}$ & Egypt & $88 / 24$ & 14.32 & 18.8 & $\begin{array}{l}\text { Case- } \\
\text { control }\end{array}$ & AITD & HPLC & - & Moderate \\
\hline
\end{tabular}


Table 1 Characteristics of included studies (Continued)

\begin{tabular}{|c|c|c|c|c|c|c|c|c|c|}
\hline Author, Year & Location & $\begin{array}{l}\text { Sample } \\
\text { size (F/M) }\end{array}$ & $\begin{array}{l}\text { Age } \\
\text { (year) }\end{array}$ & $\begin{array}{l}\text { BMI } \\
(\mathrm{kg} / \\
\left.\mathrm{m}^{2}\right) \\
\end{array}$ & $\begin{array}{l}\text { Study } \\
\text { design }\end{array}$ & $\begin{array}{l}\text { Population } \\
\text { health status }\end{array}$ & $\begin{array}{l}\text { Vit } D \text { assay } \\
\text { method }\end{array}$ & $\begin{array}{l}\text { Season of } \\
\text { sample } \\
\text { collection }\end{array}$ & $\begin{array}{l}\text { Quality } \\
\text { assessment } \\
\text { score }\end{array}$ \\
\hline Zhou et al., 2015 & USA & $1076 / 930$ & 37.8 & 26.68 & $\begin{array}{l}\text { Cross- }^{-} \\
\text {sectional }\end{array}$ & AITD & - & - & High \\
\hline $\begin{array}{l}\text { Sonmezgoz et al., } \\
2016\end{array}$ & Turkey & $76 / 68$ & 11.12 & - & $\begin{array}{l}\text { Case- } \\
\text { control }\end{array}$ & HT & CLIA & Autumn & Moderate \\
\hline Kim, 2016 & Korea & $641 / 135$ & 45.25 & 23.6 & $\begin{array}{l}\text { Cross- } \\
\text { sectional }\end{array}$ & AITD & ECLIA & All season & High \\
\hline $\begin{array}{l}\text { Giovinazzo et al, } \\
2016\end{array}$ & Italy & $175 / 25$ & 41 & 26.5 & $\begin{array}{l}\text { Case- } \\
\text { control }\end{array}$ & HT & HPLC & $\begin{array}{l}\text { Autumn, winter, } \\
\text { spring }\end{array}$ & Moderate \\
\hline $\begin{array}{l}\text { Nalbant et al., } \\
2017\end{array}$ & Turkey & $453 \mathrm{~F}$ & 40.3 & - & $\begin{array}{l}\text { Case- } \\
\text { control }\end{array}$ & HT & ECLA & $\begin{array}{l}\text { Spring, summer, } \\
\text { autumn }\end{array}$ & Moderate \\
\hline Musa et al., 2017 & $\begin{array}{l}\text { Saudi } \\
\text { Arabia }\end{array}$ & $116 \mathrm{~F}$ & 35.7 & - & $\begin{array}{l}\text { Case- } \\
\text { control }\end{array}$ & $\begin{array}{l}\text { Hypothyroid } \\
\text { patients }\end{array}$ & Spectrophotometry & $\begin{array}{l}\text { Autumn, winter, } \\
\text { spring }\end{array}$ & Moderate \\
\hline Ke et al., 2017 (a) & China & $65 / 47$ & 38.68 & 22.57 & $\begin{array}{l}\text { Case- } \\
\text { control }\end{array}$ & HT & ECLA & Autumn, winter & Moderate \\
\hline Ke et al., 2017 (b) & China & $61 / 41$ & 38.13 & 22.42 & $\begin{array}{l}\text { Case- } \\
\text { control }\end{array}$ & GD & ECLA & Autumn, winter & Moderate \\
\hline $\begin{array}{l}\text { Lawnicka et al., } \\
2017\end{array}$ & Poland & $56 / 15$ & 54.4 & - & $\begin{array}{l}\text { Case- } \\
\text { control }\end{array}$ & HT & CLIA & Winter, spring & Moderate \\
\hline Planck et al., 2017 & Sweden & $1167 / 1430$ & 52.45 & - & $\begin{array}{l}\text { Case- } \\
\text { control }\end{array}$ & GD & - & All season & Moderate \\
\hline $\begin{array}{l}\text { Mirhosseini et al., } \\
2017\end{array}$ & Canada & $515 \mathrm{~F} \& \mathrm{M}$ & 48 & 27.6 & $\begin{array}{l}\text { Case- } \\
\text { control }\end{array}$ & $\begin{array}{l}\text { Hypothyroid } \\
\text { patients }\end{array}$ & HPLC & All season & Moderate \\
\hline $\begin{array}{l}\text { Akdere G et al., } \\
2018\end{array}$ & Turkey & $66 / 94$ & 28.3 & - & $\begin{array}{l}\text { Case- } \\
\text { control }\end{array}$ & AITD+T1DM & ELISA & All season & Moderate \\
\hline Kmiec et al., 2018 & Poland & $194 / 30$ & 42 & 25.9 & $\begin{array}{l}\text { Cross- } \\
\text { sectional }\end{array}$ & $\begin{array}{l}\text { Hypothyroid } \\
\text { patients }\end{array}$ & HPLC & Summer & High \\
\hline $\begin{array}{l}\text { Komisarenko \& } \\
\text { Bobryk, } 2018 \text { (a) }\end{array}$ & Ukraine & $29 / 21$ & 39.5 & 31.25 & $\begin{array}{l}\text { Case- } \\
\text { control }\end{array}$ & AITD+T1DM & ELISA & - & Moderate \\
\hline $\begin{array}{l}\text { Komisarenko \& } \\
\text { Bobryk, } 2018 \text { (b) }\end{array}$ & Ukraine & $31 / 19$ & 57.25 & 37.25 & $\begin{array}{l}\text { Case- } \\
\text { control }\end{array}$ & AlTD + T2DM & ELISA & - & Moderate \\
\hline $\begin{array}{l}\text { Botelho et al., } \\
2018\end{array}$ & Brazil & $143 / 15$ & 46.8 & - & $\begin{array}{l}\text { Case- } \\
\text { control }\end{array}$ & HT & CLIA & Spring, summer & Low \\
\hline
\end{tabular}

F: Female, M: Male, BMI: Body Mass Index, RIA: Radio Immunoassay, CLIA: Chemiluminescence Immunoassay, HPLC: High Performance Liquid Chromatography, ALL: All seasons of the year, ELISA: Enzyme-Linked Immunosorbent Assay, HT: Hashimoto's Thyroiditis, ECLA: Euglobulin Clot Lysis Assay, GD: Graves' Disease, AITD: Autoimmune Thyroid Disease, ECLIA: Electrochemiluminescence Immunoassay, PCOS: Polycystic Ovary Syndrome, T1DM: Type 1 Diabetes Mellitus, T2DM: Type 2

Diabetes Mellitus

43, 48, 49], 3 each from Saudi Arabia [17, 32, 35], Poland [38, 52, 59], China [27, 28, 51] and Korea [54, 55, 58], 2 each from Egypt $[50,60]$ and Italy $[40,57]$ and one each from Belgium [25], Canada [33], Brazil [44], Japan [47], India [45], Sweden [46], Thailand [53], Greece, United States [56], and Ukraine [31]. Among the 35 studies, 29 recruited both genders $[25,27-32,34-41,43-46,48-56$, $58], 4$ only women [17, 42, 47, 57], and 2 studies did not report the gender [26, 33]. Eighteen studies mentioned BMI $[27,28,30,31,33,35,36,40,45,47,50-53,55-58]$ and 26 studies pointed to the time of year when samples were collected [17, 27-30, 32, 33, 36, 38-47, 49, 51, 53$55,58,61,62]$. All the included studies assessed the serum levels of $25(\mathrm{OH}) \mathrm{D}$ and none of them examined the dietary intake of vitamin $\mathrm{D}$ in participants. Additionally, among the selected studies, 6 [52-54, 56-58] were considered as high quality and the rest $[17,25-51,55]$ had moderate quality. Table 1 gives an outline of the characteristics of the included studies.

\section{Findings from the meta-analysis Serum 25(OH) D and AITD}

Thirteen datasets comprising 12,916 participants, inspected the association between serum levels of 25(OH) D and AITD status among 1886 AITD diagnosed and 11,030 non-AITD individuals [30, 31, 48-50, 53-56, 58, 62]. Vitamin D was significantly associated with AITD status (WMD $-3.1 \mathrm{ng} / \mathrm{dl}$; 95\% CI, -5.57 to - 0.66; $P=0.013)$ with significant heterogeneity $\left(\mathrm{I}^{2}=\right.$ 99.9\%, $P<0.001$ ) (Fig. 2). In other words, patients with AITD showed significantly lower serum vitamin D levels compared to non-AITD subjects. In the metabolic 


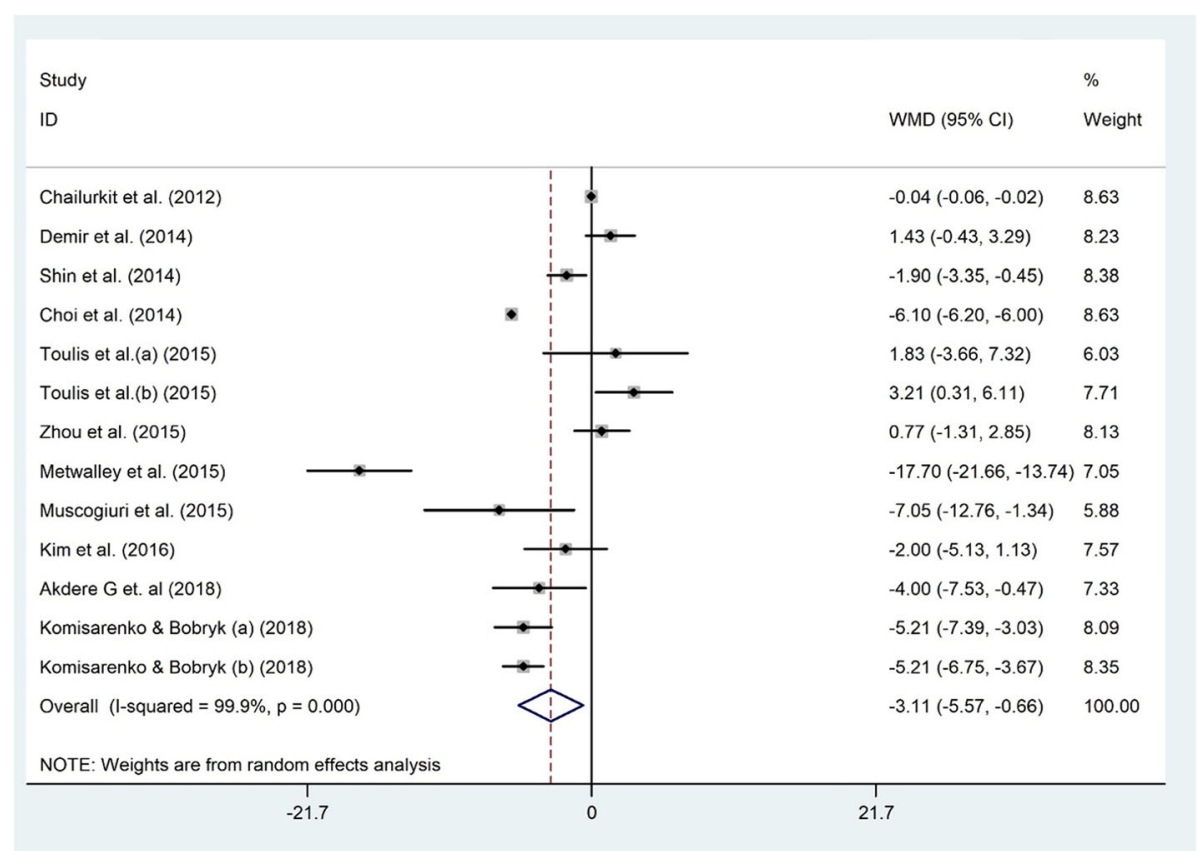

Fig. 2 The association between the serum $25(\mathrm{OH})$ D level and AITD

disorders subgroup, vitamin D and AITD were related (WMD $-3.48 \mathrm{ng} / \mathrm{dl}$; 95\% CI, -6.72 to -0.24 ). However, no significant association between vitamin D and AITD was observed in the other subgroup (Table 2). Findings from the sensitivity analysis revealed that the exclusion of Metwalley et al. study from the analysis (WMD $2.00 \mathrm{ng} / \mathrm{dl}$; $95 \% \mathrm{CI},-4.54$ to 0.53 ) [50] modified the overall effect. No evidence of publication bias was documented (Begg's test: $P=0.714$, Egger's test: $P=0.323$ ).

\section{Serum 25(OH) D and GD}

Eight citations addressed the link between serum levels of $25(\mathrm{OH}) \mathrm{D}$ and GD status among 604 GD diagnosed and 2827 non-GD individuals [25-28, 45-47, 51]. Overall, metaanalysis showed that serum vitamin $\mathrm{D}$ was not linked to $\mathrm{GD}$ (WMD $-4.14 \mathrm{ng} / \mathrm{dl} ; 95 \% \mathrm{CI},-8.46$ to $0.17 ; P=0.06$ ) and heterogeneity was significant $\left(\mathrm{I}^{2}=97.5 \%, P<0.001\right)$ (Fig. 3 ). Subgroup analyses based on age and geographical area (Table 2) showed a significant association in studies recruiting $\geq 40$ years-old subjects (WMD $-8.79 \mathrm{ng} / \mathrm{dl}$; $95 \% \mathrm{CI}$, 15.87 to -1.72 ; I2 = 98.1). Jyotsna et al. study [45] influenced the meta-analysis results (WMD $-5.04 \mathrm{ng} / \mathrm{dl} ; 95 \% \mathrm{CI},-9.62$ to -0.46$)$. Publication bias was not recognized (Begg's test: $P=0.805$, Egger's test: $P=0.542$ ).

\section{Serum 25(OH) D and $H T$}

Twelve studies with 2440 participants examined the association between $25(\mathrm{OH}) \mathrm{D}$ and HT status among 1375 HT diagnosed and 1065 healthy subjects [26-28, 3644]. The results of the meta-analysis indicated significantly lower levels of serum vitamin D among HT patients compared to healthy ones (WMD $-6.05 \mathrm{ng} / \mathrm{dl}$; $95 \% \mathrm{CI},-8.35$ to $-3.75 ; P<0.001)$ with significant heterogeneity $\left(\mathrm{I}^{2}=91.0 \% P<0.001\right)$ (Fig. 4$)$. Subgroup analyses based on participants' age and geographical area investigated the source of heterogeneity (Table 2). Keeping out the individual studies did not alter the overall meta-analysis results. Publication bias was not detected (Begg's test: $P=0.784$, Egger's test: $P=0.175$ ).

\section{Serum 25(OH) D and hypothyroidism}

Nine studies examined the relationship between serum levels of $25(\mathrm{OH}) \mathrm{D}$ and hypothyroidism among 372 hypothyroid patients and 802 healthy individuals [17, 25, 29, 32-35, 61]. Vitamin D and hypothyroidism status were significantly linked (WMD $-13.43 \mathrm{ng} / \mathrm{dl} ; 95 \% \mathrm{CI}$, -26.04 to $-0.81 ; P=0.03$ ); patients with hypothyroidism presented with lower serum vitamin $\mathrm{D}$ compared to healthy subjects. There was significant heterogeneity among the included studies $\left(\mathrm{I}^{2}=99.5 \%, \quad P<0.001\right)$ (Fig. 5). Pursuant to subgroup analysis, vitamin $\mathrm{D}$ and hypothyroidism were associated only among studies recruiting both genders (WMD $-15.43 \mathrm{ng} / \mathrm{dl}$; $95 \% \mathrm{CI}$, 29.49 to -1.37 ) and studies that included the non-Asian population (WMD $-14.31 \mathrm{ng} / \mathrm{dl}$; $95 \% \mathrm{CI},-26.53$ to 2.10) (Table 2). Keeping out a number of studies including Ucar et al. [34] (WMD - $11.33 \mathrm{ng} / \mathrm{dl}$; 95\% CI, 22.76 to 0.08 ), Mackawy et al. [32] (WMD $-11.40 \mathrm{ng} / \mathrm{dl}$; 95\% CI, -22.92 to 0.10), Mirhosseini et al. [33] (WMD $-14.41 \mathrm{ng} / \mathrm{dl} ; 95 \% \mathrm{CI},-29.01$ to 0.18 ), Fawzy et al. 
Table 2 Subgroup analysis to assess the association between serum levels of vitamin D and thyroid disorders

\begin{tabular}{|c|c|c|c|c|c|c|}
\hline Sub-grouped by & $\begin{array}{l}\text { No. of } \\
\text { studies }\end{array}$ & $\begin{array}{l}\text { Effect } \\
\text { size }^{1}\end{array}$ & $95 \% \mathrm{Cl}$ & $\begin{array}{l}I^{2} \\
(\%)\end{array}$ & $\begin{array}{l}\text { P for } \\
\text { heterogeneity }\end{array}$ & $\begin{array}{l}\mathrm{P} \text { for between subgroup } \\
\text { heterogeneity }\end{array}$ \\
\hline \multicolumn{7}{|l|}{ Hashimato } \\
\hline Age & & & & & & $<0.001$ \\
\hline Adult & 9 & -5.69 & $-8.20,-3.18$ & 89.6 & $<0.001$ & \\
\hline Adolescent & 3 & -6.81 & $-11.70,-1.93$ & 87.8 & $<0.001$ & \\
\hline Geographical population & & & & & & 0.05 \\
\hline Turkey & 6 & -6.95 & $-11.15,-2.75$ & 91.2 & $<0.001$ & \\
\hline Other countries & 6 & -5.35 & $-9.13,-1.58$ & 92 & $<0.001$ & \\
\hline \multicolumn{7}{|l|}{ Hypothyroid } \\
\hline Gender & & & & & & 0.057 \\
\hline Both sex & 8 & -15.43 & $-29.49,-1.37$ & 99.6 & $<0.001$ & \\
\hline Female & 1 & 2.60 & $-1.38,6.58$ & - & - & \\
\hline Geographical population & & & & & & $<0.001$ \\
\hline Asian & 4 & -12.34 & $-31.89,7.20$ & 99.3 & $<0.001$ & \\
\hline Non-Asian & 5 & -14.31 & $\begin{array}{l}-26.53,- \\
2.10\end{array}$ & 98.6 & $<0.001$ & \\
\hline \multicolumn{7}{|l|}{ Grave disease } \\
\hline Geographical population & & & & & & $<0.001$ \\
\hline Asian & 6 & -1.74 & $-3.95,0.46$ & 80.2 & $<0.001$ & \\
\hline Non-Asian & 2 & -7.10 & $-18.47,4.25$ & 99.3 & $<0.001$ & \\
\hline Participants age & & & & & & $<0.001$ \\
\hline$\geq 40$ years old & 4 & -8.79 & $-15.87,-1.72$ & 98.1 & $<0.001$ & \\
\hline$<40$ years old & 4 & -0.54 & $-2.07,0.98$ & 54.3 & 0.08 & \\
\hline \multicolumn{7}{|l|}{ AITD } \\
\hline Geographical population & & & & & & $<0.001$ \\
\hline Asian & 6 & -2.08 & $-5.6,1.43$ & 100 & $<0.001$ & \\
\hline Non-Asian & 7 & -4.13 & $-8.31,0.05$ & 93.9 & $<0.001$ & \\
\hline Study design & & & & & & $<0.001$ \\
\hline Case control & 7 & -3.65 & $-7.75,0.44$ & 94.4 & $<0.001$ & \\
\hline Cross-sectional & 6 & -2.52 & $-6.10,1.04$ & 100 & $<0.001$ & \\
\hline Participants health status & & & & & & $<0.001$ \\
\hline With metabolic disorders & 5 & -3.48 & $-6.72,-0.24$ & 85.9 & $<0.001$ & \\
\hline $\begin{array}{l}\text { Without metabolic } \\
\text { disorders }\end{array}$ & 8 & -2.87 & $-5.97,0.23$ & 99.9 & $<0.001$ & \\
\hline
\end{tabular}

${ }^{1}$ Calculated by Random-effects model

(a) [29] (WMD - $11.98 \mathrm{ng} / \mathrm{dl}$; $95 \% \mathrm{CI},-24.84$ to 0.86 ) and Fawzy et al. (b) [29] (WMD - $11.10 \mathrm{ng} / \mathrm{dl} ; 95 \% \mathrm{CI},-22.33$ to 0.13$)$ modified the overall effect. Due to evidence of publication bias (Begg's test: $P=0.835$, Egger's test: $P=$ $0.006)$, possible un-detected studies were tracked by trim and fill analysis, but this method could not add any dataset to our included ones.

\section{Discussion}

As far as we know, this is the first comprehensive attempt to examine the association between serum levels of vitamin D and thyroid disorders in form of a systematic review and meta-analysis. It revealed that vitamin $\mathrm{D}$ was significantly associated with hypothyroidism, AITD, and HT. Furthermore, vitamin D was significantly lower among $\geq 40$-year-old GD subjects. Some issues should be considered when elucidating the results. First of all, there were substantial inter-assay differences in the performance of commercially available kits for serum vitamin D assay [63]. This notion may impact the results and play a considerable role as a heterogeneity factor. Also, seasonal variation in serum vitamin $\mathrm{D}$ should be 


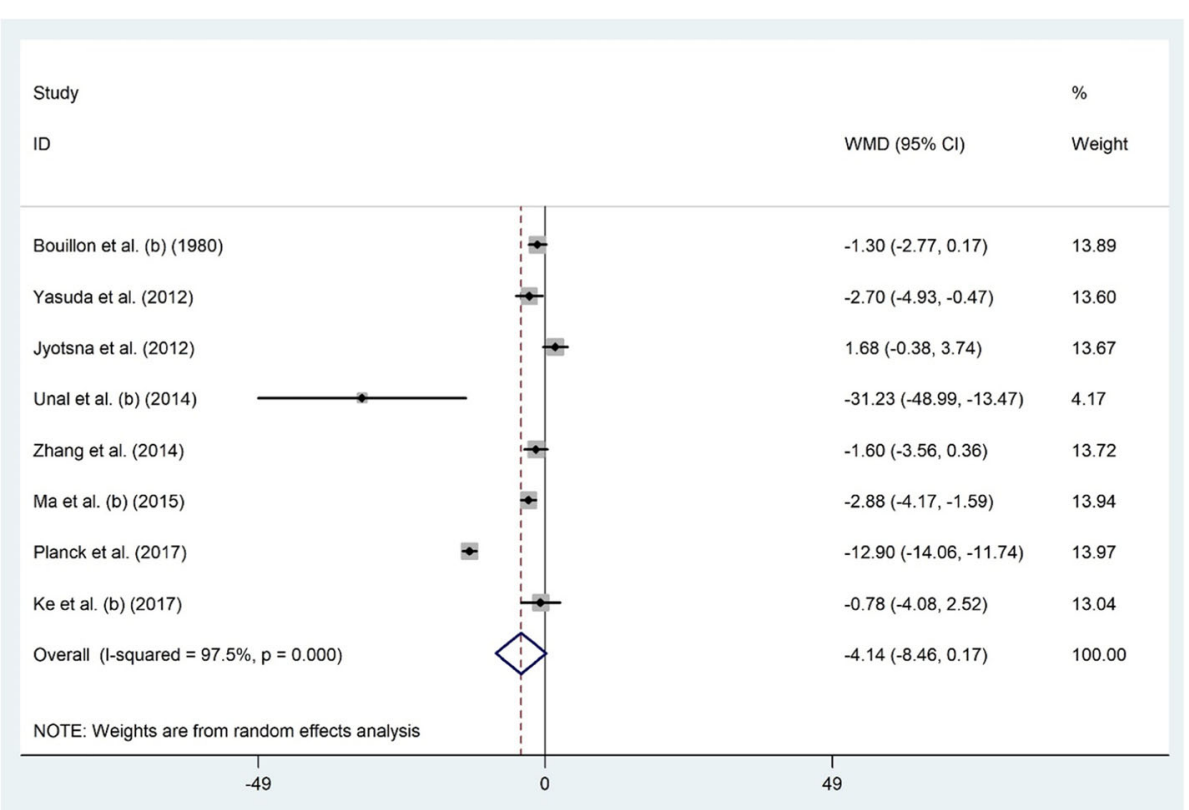

Fig. 3 The association between the serum 25(OH) D level and GD

kept in mind when interpreting the results [64]. This fact has been excused in some papers $[25,26,31,34,35$, $37,46,48,50,56]$. Inconsistencies in terms of the season of sample collection could also influence our final results. Besides, it has been proven that the bioavailability of vitamin $\mathrm{D}$ diminishes among overweight/obese individuals [65]; however, most of the included articles disregarded BMI as a confounding factor and probable source of heterogeneity $[17,18,25,26,29,32,34,37-39$, $41-44,46,48,49,54]$.

Pursuant to previous reports, the role of vitamin D in immunity is through producing anti-inflammatory and immune-regulatory markers via VDR expression in the nucleus of cells [66]. VDR is involved in cellular

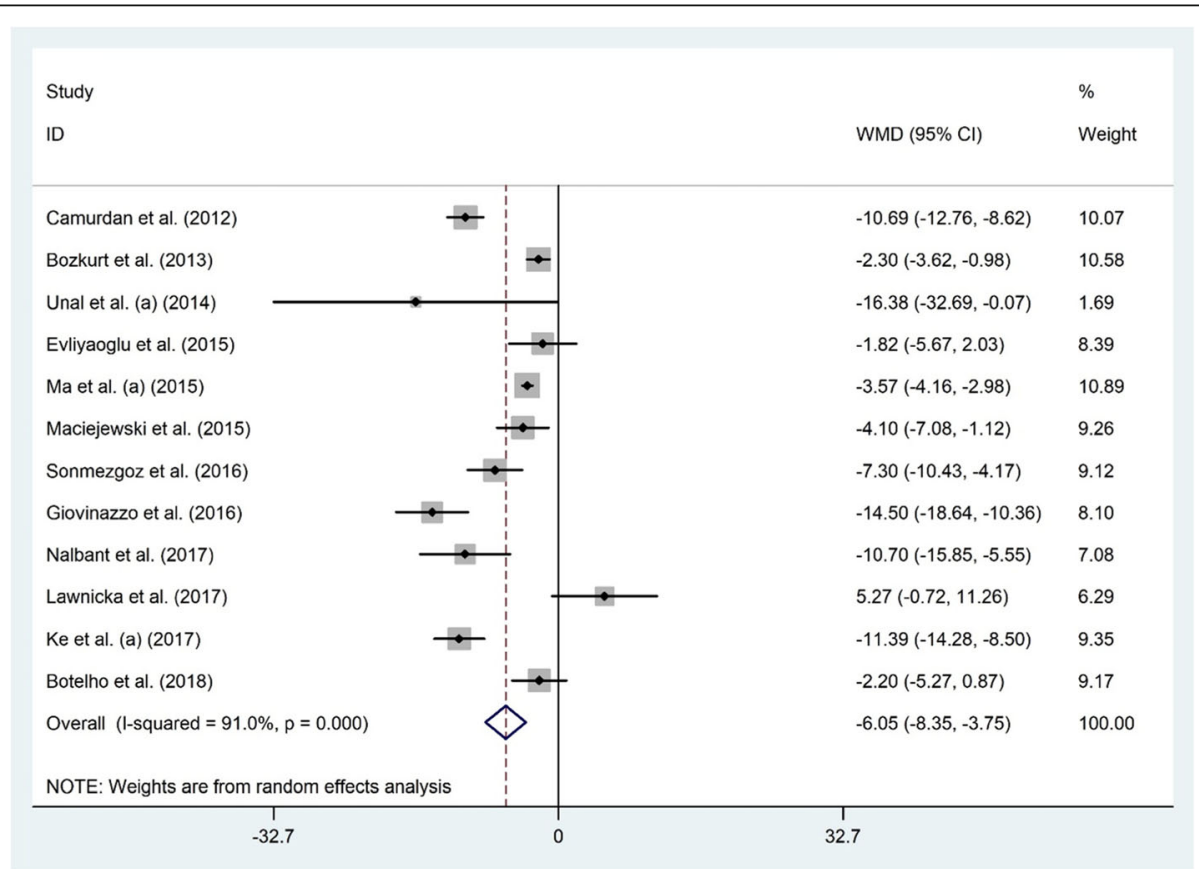

Fig. 4 The association between the serum $25(\mathrm{OH}) \mathrm{D}$ level and HT 


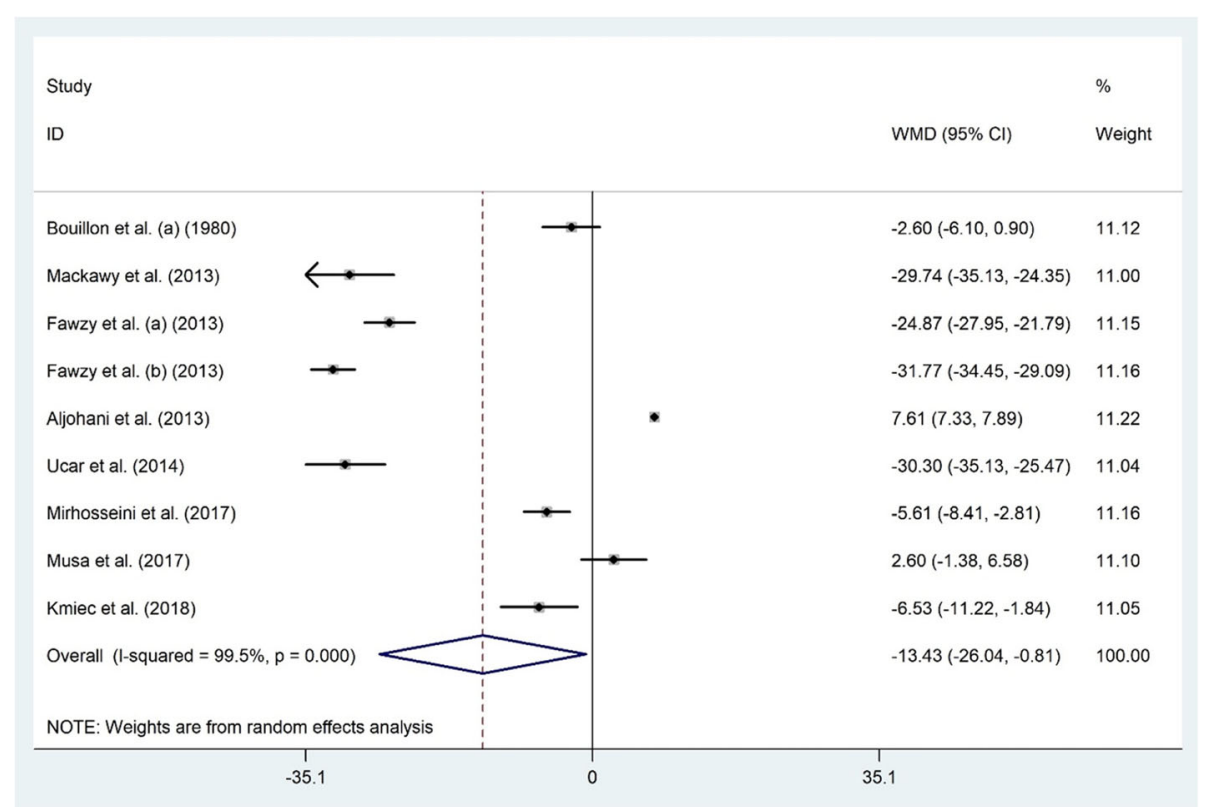

Fig. 5 The association between the serum $25(\mathrm{OH}) \mathrm{D}$ level and hypothyroidism

immunity function by stimulating innate and adaptive immune responses [66]. Polymorphisms of the VDR are related to the predisposition of people to thyroid disorders such as hypothyroidism [12, 67]. VDR modulates the effects of vitamin D as its specific and intracellular receptor. Polymorphisms of the VDR gene may decrease vitamin D activity [12]. Through a meta-analysis, Wang et al., reported a significant link between VDR gene polymorphisms and autoimmune thyroid disorders in diverse ethnic groups [66]. Vitamin D has hindering effects on the production of inflammatory cytokines such as interleukin (IL)-1, IL-6, IL-8, IL-12, and tumor necrosis factor (TNF)- $\alpha[68,69]$. Also, it suppresses dendritic cell differentiation and maturation via a reduced expression of the major histocompatibility complex (MHC) class II molecules, co-stimulatory molecules, and IL-12 [68, 69]. Additionally, vitamin $\mathrm{D}$ makes the induction of $\mathrm{T}$ regulatory cells simpler to diminish $\mathrm{T}$ cell-dependent immune responses in autoimmune diseases [68, 69]. $\mathrm{T}$ and $\mathrm{B}-$ cells reaction to thyroid antigens in geneticallyvulnerable subjects lead to $\mathrm{HT}$ [42]. Based on previous studies, serum levels of $25-\mathrm{OH}$ D3 $<20 \mathrm{ng} / \mathrm{mL}$ can exacerbate positive thyroid autoantibodies such as antithyroid peroxidase (TPOAb) and anti-thyroglobulin (TgAb) [70-72]. Additionally, high serum levels of calcium and phosphorous and low levels of circulating parathyroid hormone may inhibit renal $25(\mathrm{OH}) \mathrm{D} 1-\alpha$ hydroxylase function [17]. Thus, due to lower production of 1,25 $(\mathrm{OH}) 2 \mathrm{D}$, serum 24,25 $(\mathrm{OH}) \mathrm{D}$ and thyroid hormone levels will be higher [17]. Overall, vitamin D could contribute to the prevention or correction of hypothyroidism and improvement of thyroid function [17].

The limitations of this study are as follows. There was significant heterogeneity in our study that may have affected the results and diminished the generalizability of the outcomes. The probable sources of heterogeneity might be differences in age, gender, BMI, study design, vitamin D assay methods and kits, the season of sample collection, geographical variation, and quality of the studies. Moreover, the nature of cross-sectional studies makes it impossible to draw a causal link between variables. Furthermore, there was no information regarding dietary vitamin $\mathrm{D}$ intake that could have affected serum levels of vitamin D.

\section{Conclusion}

In the present systematic review and meta-analysis, vitamin D levels were significantly lower in hypothyroidism, AITD, and HT patients compared to healthy people. However, there was no significant association between serum vitamin $\mathrm{D}$ and GD, except among subjects $\geq 40$ years old. The effect sizes of the included studies showed significant heterogeneity which might affect the interpretation of results. Further well-designed prospective cohort studies and clinical trials are needed for a better understanding of the relationship between vitamin D and thyroid disorders.

\section{Abbreviations}

Vitamin D: Vitamin D; VDR: Vitamin D Receptor; AITD: Autoimmune thyroid disease; HT: Hashimoto's thyroiditis; GD: Graves' disease; PRISMA: Preferred 
reporting items for systematic reviews and meta-analysis; OR: Odds ratio; $\mathrm{Cl}$ : Confidence intervals; BMI: Body mass index; WMD: Weighted mean difference; SD: Standard deviation; SE: Standard error; IL: Interleukin; TNF: Tumor necrosis factor; MHC: Major Histocompatibility Complex; TPOAb: Anti-thyroid peroxidase Antibody; TgAb: Anti-thyroglobine Antibody

\section{Acknowledgments}

None.

\section{Authors' contributions}

A.A, S. T and G. A contributed to the conception of research. A. A, A. H and S. T searched databases, screened articles and extracted data. A. A and A. F performed statistical analysis; and all authors contributed to the writing and revision of the manuscript. The author(s) read and approved the final manuscript.

\section{Funding}

This research did not receive any specific grant from funding agencies in the public, commercial, or not-for-profit sectors.

\section{Availability of data and materials}

The data that support the findings of this study are available from the corresponding author upon reasonable request.

\section{Declarations}

Ethics approval and consent to participate

All analyses were based on previously published studies; thus, no ethical approval isrequired.

\section{Consent for publication}

Not applicable.

\section{Competing interests}

The authors declare no conflict of interest.

\section{Author details}

'Student Research Committee, Department of Community Nutrition, Schoo of Nutrition and Food Science, Isfahan University of Medical Sciences, Isfahan, Iran. ${ }^{2}$ Department of Community Nutrition, School of Nutrition and Food Science, Food Security Research Center, Isfahan University of Medical Sciences, Isfahan, Iran. ${ }^{3}$ Department of Clinical Nutrition, School of Nutrition and Food Science, Food Security Research Center, Isfahan University of Medical Sciences, Isfahan, Iran. ${ }^{4}$ School of Sport and Exercise Sciences, Faculty of Science, Liverpool John Moores University, Liverpool, UK.

Received: 21 November 2020 Accepted: 30 July 2021

Published online: 21 August 2021

\section{References}

1. Skaaby T, Husemoen LLN, Thuesen BH, Linneberg A. Prospective population-based study of the association between vitamin D status and incidence of autoimmune disease. Endocrine. 2015;50(1):231-8. https://doi. org/10.1007/s12020-015-0547-4

2. Vatandost $\mathrm{S}$, Jahani $M$, Afshari $A$, Amiri MR, Heidarimoghadam $R$, Mohammadi Y. Prevalence of vitamin D deficiency in Iran: a systematic review and meta-analysis. Nutr Health. 2018;24(4):269-78. https://doi.org/1 $0.1177 / 0260106018802968$

3. Hassan-Smith ZK, Hewison M, Gittoes NJ. Effect of vitamin D deficiency in developed countries. Br Med Bull. 2017;122(1):79-89. https://doi.org/10.1 093/bmb/ldx005.

4. Kelishadi R, Qorbani M, Motlagh ME, Heshmat R, Poursafa P, Bahreynian M. Prevalence of vitamin D deficiency according to climate conditions among a nationally representative sample of Iranian adolescents: the CASPIAN-III study. Int J Pediatr. 2016;4(6):1903-10.

5. Cashman KD, Dowling KG, Škrabáková Z, Gonzalez-Gross M, Valtueña J, De Henauw S, et al. Vitamin D deficiency in Europe: pandemic? Am J Clin Nutr. 2016;103(4):1033-44. https://doi.org/10.3945/ajcn.115.120873.

6. LeFevre ML. Screening for vitamin D deficiency in adults: US preventive services task force recommendation statement. Ann Intern Med. 2015 162(2):133-40. https://doi.org/10.7326/M14-2450.
7. Arabi A, El Rassi R, Fuleihan GE-H. Hypovitaminosis D in developing countries - prevalence, risk factors and outcomes. Nat Rev Endocrinol. 2010; 6(10):550-61. https://doi.org/10.1038/nrendo.2010.146.

8. Pludowski P, Holick MF, Pilz S, Wagner CL, Hollis BW, Grant WB, et al. Vitamin D effects on musculoskeletal health, immunity, autoimmunity, cardiovascular disease, cancer, fertility, pregnancy, dementia and mortality—a review of recent evidence. Autoimmun Rev. 2013;12(10):97689. https://doi.org/10.1016/j.autrev.2013.02.004.

9. Spiro A, Buttriss J. Vitamin D: an overview of vitamin D status and intake in E urope. Nutr Bull. 2014;39(4):322-50. https://doi.org/10.1111/nbu.12108.

10. Hossein-nezhad A, Holick MF: Vitamin D for health: a global perspective. In: Mayo clinic proceedings: 2013: Elsevier; 2013: 720-755.

11. Ławnicka H, Galant-Gdula A, Motylewska E, Komorowski J, Świętosławski J, Stępień H. Estimation of vitamin D status in patients with secondary and primary hypothyroidism of different etiology. Neuroendocrinol Lett. 2017; 38(8):565-74.

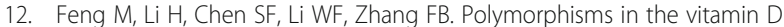
receptor gene and risk of autoimmune thyroid diseases: a meta-analysis. Endocrine. 2013;43(2):318-26. https://doi.org/10.1007/s12020-012-9812-y.

13. Maenhaut C, Christophe D, Vassart G, Dumont J, Roger P, Opitz R: Ontogeny, anatomy, metabolism and physiology of the thyroid. In: Endotext [Internet]. edn.: MDText. com, Inc.; 2015.

14. Degroot $L$, Quintans J. The causes of autoimmune thyroid disease. Endocr Rev. 1989;10(4):537-62. https://doi.org/10.1210/edrv-10-4-537.

15. Nettore IC, Albano L, Ungaro P, Colao A, Macchia PE. Sunshine vitamin and thyroid. Reviews in Endocrine and Metabolic Disorders. 2017;18(3):347-54. https://doi.org/10.1007/s11154-017-9406-3.

16. Goswami R, Marwaha RK, Gupta N, Tandon N, Sreenivas V, Tomar N, et al. Prevalence of vitamin D deficiency and its relationship with thyroid autoimmunity in Asian Indians: a community-based survey. Br J Nutr. 2009; 102(3):382-6. https://doi.org/10.1017/S0007114509220824.

17. Musa IR, Gasim Gl, Khan S, Ibrahim IA, Abo-alazm H, Adam I. No association between $25(\mathrm{OH})$ vitamin D level and hypothyroidism among females. Open access Macedonian journal of medical sciences. 2017;5(2):126-30. https://doi.org/10.3889/oamjms.2017.029.

18. Effraimidis G, Badenhoop K, Tijssen JG, Wiersinga WM. Vitamin D deficiency is not associated with early stages of thyroid autoimmunity. Eur J Endocrinol. 2012;167(1):43-8. https://doi.org/10.1530/EJE-12-0048.

19. Moher D, Shamseer L, Clarke M, Ghersi D, Liberati A, Petticrew M, et al. Preferred reporting items for systematic review and meta-analysis protocols (PRISMA-P) 2015 statement. Syst Rev. 2015;4(1):1. https://doi.org/10.1186/204 6-4053-4-1.

20. Peterson J, Welch V, Losos M, Tugwell P. The Newcastle-Ottawa scale (NOS) for assessing the quality of nonrandomised studies in meta-analyses. Ottawa: Ottawa Hospital Research Institute; 2011.

21. Uhland AM, Kwiecinski GG, DeLuca HF. Normalization of serum calcium restores fertility in vitamin D-deficient male rats. J Nutr. 1992;122(6):1338-44. https://doi.org/10.1093/jn/122.6.1338.

22. Von Hippel PT. Mean, median, and skew: Correcting a textbook rule. J Stat Educ. 2005;13(2):1-13.

23. Green S, Higgins J: Cochrane handbook for systematic reviews of interventions. In: Version; 2005.

24. Yang $\mathrm{CH}$, Albietz J, Harkin DG, Kimlin MG, Schmid KL. Impact of oral vitamin D supplementation on the ocular surface in people with dry eye and/or low serum vitamin D. Contact lens \& anterior eye : the journal of the British Contact Lens Association. 2018;41(1):69-76. https://doi.org/10.1016/j.clae.201 7.09.007.

25. Bouillon R, Muls E, De Moor P. Influence of thyroid function on the serum concentration of 1,25-dihydroxyvitamin D3. J Clin Endocrinol Metab. 1980; 51(4):793-7. https://doi.org/10.1210/jcem-51-4-793.

26. Unal AD, Tarcin O, Parildar $\mathrm{H}$, Cigerli $\mathrm{O}$, Eroglu H, Demirag NG. Vitamin D deficiency is related to thyroid antibodies in autoimmune thyroiditis. Central European Journal of Immunology. 2014;39(4):493-7. https://doi.org/10.5114/ ceji.2014.47735

27. Ma J, Wu D, Li C, Fan C, Chao N, Liu J, et al. Lower serum 25Hydroxyvitamin D level is associated with 3 types of autoimmune thyroid diseases. Medicine. 2015;94(39):e1639. https://doi.org/10.1097/MD. 0000000000001639

28. Ke W, Sun T, Zhang Y, He L, Wu Q, Liu J, et al. 25-Hydroxyvitamin D serum level in Hashimoto's thyroiditis, but not Graves' disease is relatively deficient Endocr J. 2017;64(6):581-7. https://doi.org/10.1507/endocrj.EJ16-0547. 
29. Fawzy E, MD, Mohamed SA-S, Shebl M, El-Rabat AM. Hypovitaminosis d in autoimmune hypothyroidism. Journal Of American Science. 2013;9(11):60-5.

30. Toulis K, Tsekmekidou X, Potolidis E, Didangelos T, Gotzamani-Psarrakou A, Zebekakis $\mathrm{P}$, et al. Thyroid autoimmunity in the context of type 2 diabetes mellitus: implications for vitamin D. Int J Endocrinol. 2015;2015:1-5. https:// doi.org/10.1155/2015/710363.

31. Komisarenko Yl, Bobryk MI. Vitamin D deficiency and immune disorders in combined endocrine pathology. Front Endocrinol. 2018;9. https://doi.org/1 0.3389/fendo.2018.00600.

32. Mackawy AMH, Al-Ayed BM, Al-Rashidi BM. Vitamin D deficiency and its association with thyroid disease. Int J Health Sci. 2013;7(3):267-75. https:// doi.org/10.12816/0006054.

33. Mirhosseini N, Brunel L, Muscogiuri G, Kimball S. Physiological serum 25hydroxyvitamin D concentrations are associated with improved thyroid function-observations from a community-based program. Endocrine. 2017; 58(3):563-73. https://doi.org/10.1007/s12020-017-1450-y.

34. Ucar F, Akyol S, Ozturk G, Ginis Z, Erden G, Taslipinara MY, et al. Evaluation of serum vitamin $D$ levels in elderly patients with subclinical hypothyroidism. J Exper Clin Med (Turkey). 2014;31(2):77-80. https://doi. org/10.5835/jecm.omu.31.02.003.

35. Aljohani NJ, Al-Daghri NM, Al-Attas OS, Alokail MS, Alkhrafy KM, Al-Othman $A$, et al. Differences and associations of metabolic and vitamin D status among patients with and without sub-clinical hypothyroid dysfunction. BMC Endocr Disord. 2013;13(1). https://doi.org/10.1186/1472-6823-13-31.

36. Bozkurt NC, Karbek B, Ucan B, Sahin M, Cakal E, Ozbek M, et al. THE ASSOCIATION BETWEEN SEVERITY OF VITAMIN D DEFICIENCY AND HASHIMOTO'S THYROIDITIS. Endocr Pract. 2013;19(3):479-84. https://doi. org/10.4158/EP12376.OR

37. Camurdan OM, Doger E, Bideci A, Celik N, Cinaz P. Vitamin D status in children with Hashimoto thyroiditis. Journal of pediatric endocrinology \& metabolism : JPEM. 2012;25(5-6):467-70.

38. Ławnicka H, Galant-Gdula A, Motylewska E, Komorowski J, Świętosławski J, Stępień $H$. Estimation of vitamin D status in patients with secondary and primary hypothyroidism of different etiology. Neuroendocrinol Lett. 2017; 38(8):565-74.

39. Evliyaoglu O, Acar M, Ozcabi B, Erginoz E, Bucak F, Ercan O, et al. Vitamin D deficiency and Hashimoto's thyroiditis in children and adolescents: a critical vitamin D level for this association? Journal of clinical research in pediatric endocrinology. 2015;7(2):128-33. https://doi.org/10.4274/jcrpe.2011.

40. Giovinazzo S, Vicchio TM, Certo R, Alibrandi A, Palmieri O, Campenni A, et al. Vitamin D receptor gene polymorphisms/haplotypes and serum 25(OH)D3 levels in Hashimoto's thyroiditis. Endocrine. 2016;55(2):599-606. https://doi. org/10.1007/s12020-016-0942-5.

41. Maciejewski A, Wojcicka M, Roszak M, Losy J, Lacka K. Assessment of vitamin $\mathrm{D}$ level in autoimmune thyroiditis patients and a control Group in the Polish Population. Adv Clin Exp Med. 2015;24(5):801-6. https://doi.org/10.1 7219/acem/29183.

42. Nalbant A, Gokosmanoglu F, Cinemre H, Varim C, Kaya T, Ergenc H. The relation between serum vitamin D levels and Hashimoto thyroiditis in women. Kuwait Med J. 2017;49(3):223-6.

43. Sönmezgöz E, Ozer S, Yilmaz R, Önder Y, Bütün I, Bilge S. Hypovitaminosis d in children with hashimoto's thyroiditis. Revista Medica de Chile. 2016; 144(5):611-6. https://doi.org/10.4067/S0034-98872016000500009.

44. Botelho IMB, Moura Neto A, Silva CA, Tambascia MA, Alegre SM, ZantutWittmann DE. Vitamin D in Hashimoto's thyroiditis and its relationship with thyroid function and inflammatory status. Endocr J. 2018;65(10):1029-37. https://doi.org/10.1507/endocrj.EJ18-0166.

45. Jyotsna VP, Sahoo A, Ksh SA, Sreenivas V, Gupta N. Bone mineral density in patients of graves disease pre- \& post-treatment in a predominantly vitamin D deficient population. Indian J Med Res. 2012;135(1):36-41. https://doi. org/10.4103/0971-5916.93422

46. Planck T, Shahida B, Malm J, Manjer J. Vitamin D in graves disease: levels, correlation with laboratory and clinical parameters, and genetics. Eur Thyroid J. 2017;7(1):27-33. https://doi.org/10.1159/000484521.

47. Yasuda T, Okamoto Y, Hamada N, Miyashita K, Takahara M, Sakamoto F, et al. Serum vitamin D levels are decreased and associated with thyroid volume in female patients with newly onset Graves' disease. Endocrine. 2012;42(3):739-41. https://doi.org/10.1007/s12020-012-9679-y.

48. Demir K, Keskin M, Kor Y, Karaoglan M, Bulbul OG. Autoimmune thyroiditis in children and adolescents with type 1 diabetes mellitus is associated with elevated IgG4 but not with low vitamin D. Hormones Int J Endocrinol Metab. 2014;13(3):361-8.

49. Akdere G, Efe B, Sisman P, Yorulmaz G. The relationship between vitamin D level and organ-specific autoimmune disorders in newly diagnosed type I diabetes mellitus. Bratislava Med J Bratislavske Lekarske Listy. 2018;119(9): 544-9. https://doi.org/10.4149/BLL 2018098.

50. Metwalley KA, Farghaly HS, Sherief T, Hussein A. Vitamin D status in children and adolescents with autoimmune thyroiditis. J Endocrinol Investig. 2015; 39(7):793-7.

51. Zhang $H$, Liang $L$, Xie Z. Low vitamin $D$ status is associated with increased thyrotropin-receptor antibody titer in graves disease. Endocr Pract. 2014; 21(3):258-63.

52. Kmieć P, Minkiewicz I, Rola R, Sworczak K, Żmijewski MA, Kowalski K. Vitamin D status including 3-epi-25 $(\mathrm{OH})$ D3 among adult patients with thyroid disorders during summer months. Endokrynologia Polska. 2018;69(6):653-60. https://doi.org/10.5603/EP.a2018.0065.

53. Chailurkit LO, Aekplakorn W, Ongphiphadhanakul B. High vitamin D status in younger individuals is associated with low circulating thyrotropin. Thyroid. 2012;23(1):25-30. https://doi.org/10.1089/thy.2012.0001.

54. Shin DY, Kim KJ, Kim D, Hwang S, Lee EJ. Low serum vitamin D is associated with anti-thyroid peroxidase antibody in autoimmune thyroiditis. Yonsei Med J. 2014;55(2):476-81. https://doi.org/10.3349/ymj.2014.55.2.476.

55. Choi YM, Kim WG, Kim TY, Bae SJ, Kim HK, Jang EK, et al. Low levels of serum vitamin D3 are associated with autoimmune thyroid disease in premenopausal women. Thyroid : official journal of the American Thyroid Association. 2014;24(4):655-61. https://doi.org/10.1089/thy.2013.0460.

56. Zhou P, Cai JN, Markowitz M. Absence of a relationship between thyroid hormones and vitamin D levels. J Pediatr Endocrinol Metab. 2015;29(6):7037.

57. Muscogiuri G, Palomba S, Caggiano M, Tafuri D, Colao A, Orio F. Low 25 $(\mathrm{OH})$ vitamin D levels are associated with autoimmune thyroid disease in polycystic ovary syndrome. Endocrine. 2015;53(2):538-42. https://doi.org/1 0.1007/s12020-015-0745-0.

58. Kim D. Low vitamin D status is associated with hypothyroid Hashimoto's thyroiditis. Hormones Int J Endocrinol Metab. 2016;15(3):385-93.

59. Maciejewski A, Wojcicka M, Roszak M, Losy J, Lacka K. Assessment of vitamin $D$ level in autoimmune thyroiditis patients and a control Group in the Polish Population. Advances in clinical and experimental medicine : official organ Wroclaw Medical University. 2015;24(5):801-6. https://doi.org/10.1721 9/acem/29183.

60. Esmat Fawzy M, Mohamed SA-S, Shebl M, El-Rabat AM. Hypovitaminosis d in autoimmune hypothyroidism. Journal Of American Science. 2013;9(11):605.

61. Kmiec P, Minkiewicz I, Rola R, Sworczak K, Zmijewski MA, Kowalski K. Vitamin D status including 3-epi-25(OH)D-3 among adult patients with thyroid disorders during summer months. Endokrynologia Polska. 2018;69(6):653-60 https://doi.org/10.5603/EP.a2018.0065.

62. Muscogiuri G, Tirabassi G, Bizzaro G, Orio F, Paschou SA, Vryonidou A, et al. Vitamin D and thyroid disease: to D or not to D? Eur J Clin Nutr. 2015;69(3): 291-6. https://doi.org/10.1038/ejen.2014.265.

63. Snellman G, Melhus H, Gedeborg R, Byberg L, Berglund L, Wernroth L, et al. Determining vitamin $D$ status: a comparison between commercially available assays. PLoS One. 2010;5(7):e11555. https://doi.org/10.1371/journal. pone.0011555.

64. Diffey B. Modelling the seasonal variation of vitamin D due to sun exposure. Br J Dermatol. 2010;162(6):1342-8. https://doi.org/10.1111/j.1365-2133.2010. 09697.x.

65. Wortsman J, Matsuoka LY, Chen TC, Lu Z, Holick MF. Decreased bioavailability of vitamin D in obesity. Am J Clin Nutr. 2000;72(3):690-3. https://doi.org/10.1093/ajcn/72.3.690.

66. Wang $X$, Cheng W, Ma Y, Zhu J. Vitamin D receptor gene Fokl but not Taql, Apal, Bsml polymorphism is associated with Hashimoto's thyroiditis: a metaanalysis. Sci Rep. 2017;7(1):1-11.

67. Yazici D, Yavuz D, Tarcin O, Sancak S, Deyneli O, Akalin S. Vitamin D receptor gene Apal, Taql, Fokl and Bsml polymorphisms in a group of Turkish patients with Hashimoto's thyroiditis. Minerva Endocrinol. 2013;38(2):195-201.

68. Altieri B, Muscogiuri G, Barrea L, Mathieu C, Vallone CV, Mascitelli L, et al. Does vitamin $D$ play a role in autoimmune endocrine disorders? A proof of concept. Rev Endocr Metab Disord. 2017;18(3):335-46. https://doi.org/10.1 007/s11154-016-9405-9. 
69. Aranow C. Vitamin D and the immune system. J Investig Med. 2011;59(6): 881-6. https://doi.org/10.2310/JIM.0b013e31821b8755.

70. Wang X, Zynat J, Guo Y, Osiman R, Tuhuti A, Zhao H, et al. Low serum vitamin $D$ is associated with anti-thyroid-globulin antibody in female individuals. Int J Endocrinol. 2015;2015:285290.

71. Zhang Q, Sun M, Wang Z, Fu Q, Shi Y, Yang F, et al. Relationship between serum 25 -hydroxy vitamin $\mathrm{D}$ and thyroid autoimmunity among middleaged and elderly individuals. Acta Univ Med Nanjing (Nat Sci). 2014;34:4869.

72. Łacka K, Maciejewski A. Vitamin D in the etiopathogenesis of autoimmune thyroiditis. Polski Merkuriusz Lekarski. 2013;34(203):281-5.

\section{Publisher's Note}

Springer Nature remains neutral with regard to jurisdictional claims in published maps and institutional affiliations.

Ready to submit your research? Choose BMC and benefit from:

- fast, convenient online submission

- thorough peer review by experienced researchers in your field

- rapid publication on acceptance

- support for research data, including large and complex data types

- gold Open Access which fosters wider collaboration and increased citations

- maximum visibility for your research: over $100 \mathrm{M}$ website views per year

At BMC, research is always in progress.

Learn more biomedcentral.com/submissions 